\title{
Prevalence and associated factors of adolescent pregnancy (15-19 years) in East Africa: a multilevel analysis
}

\author{
Misganaw Gebrie Worku ${ }^{1 *}$, Zemenu Tadesse Tessema², Achamyeleh Birhanu Teshale², \\ Getayeneh Antehunegn Tesema ${ }^{2}$ and Yigizie Yeshaw ${ }^{2,3}$
}

\begin{abstract}
Background: Adolescent pregnancy is a major public health problem both in developed and developing countries with huge consequences to maternal health and pregnancy outcomes. However, there is limited evidence on the prevalence and associated factors of adolescent pregnancy in East Africa. Therefore, this study aimed to investigate the prevalence and associated factors of adolescent pregnancy in Eastern Africa.

Method: The most recent Demographic and Health Survey (DHS) datasets of the 12 East African countries were used. A total weighted sample of 17, 234 adolescent girls who ever had sex was included. A multilevel binary logistic regression analysis was fitted to identify the significantly associated factors of adolescent pregnancy. Finally, the Adjusted Odds Ratio (AOR) with 95\% Confidence Interval (CI) were reported to declare the factors that are significantly associated with adolescent pregnancy.

Results: The overall prevalence of adolescent pregnancy in East Africa was 54.6\% (95\%Cl: 53.85, 55.34\%). In the multivariable multilevel analysis; being age $18-19$ years $[\mathrm{AOR}=3.06 ; 95 \% \mathrm{Cl}: 2.83,3.31]$, using contraceptive $[\mathrm{AOR}=$ $1.41 ; 95 \% \mathrm{Cl}: 1.28,1.55]$, being employed girls $[\mathrm{AOR}=1.11 ; 95 \% \mathrm{Cl}: 1.03,1.19]$, being spouse/head within the family $[A O R=1.62 ; 95 \% \mathrm{Cl}: 1.45,1.82]$, and being from higher community level contraceptive utilization $[\mathrm{AOR}=1.10 ; 95 \% \mathrm{Cl}$ : $1.02,1.19]$ were associated with higher odds of adolescent pregnancy. While adolescent girls attained secondary education and higher $[\mathrm{AOR}=0.78 ; 95 \% \mathrm{Cl}: 0.68,0.91]$, initiation of sex at age of 15 to 14 years $[\mathrm{AOR}=0.69 ; 95 \% \mathrm{Cl}$ : $0.63,0.75$ ] and 18 to 19 years [AOR $=0.31 ; 95 \% \mathrm{Cl}: 0.27,0.35$ ], being unmarried [AOR $=0.25 ; 95 \% \mathrm{Cl}: 0.23,0.28]$, having media exposure [AOR $=0.85 ; 95 \% \mathrm{Cl}: 0.78,0.92]$, and being girls from rich household [AOR $=0.64 ; 95 \% \mathrm{Cl}: 0.58,0.71]$ were associated with lower odds of adolescent pregnancy.

Conclusion: This study found that adolescent pregnancy remains a common health care problem in East Africa. Age, contraceptive utilization, marital status, working status, household wealth status, community-level contraceptive utilization, age at initiation of sex, media exposure, educational level and relation to the household head were associated with adolescent pregnancy. Therefore, designing public health interventions targeting higher risk adolescent girls such as those from the poorest household through enhancing maternal education and empowerment is vital to reduce adolescent pregnancy and its complications.
\end{abstract}

Keywords: Adolescent pregnancy, East Africa, Multilevel analysis

\footnotetext{
* Correspondence: misgeb2008@gmail.com

'Department of Human Anatomy, College of Medicine and Health Science,

School of Medicine, University of Gondar, Gondar, Ethiopia

Full list of author information is available at the end of the article
}

(c) The Author(s). 2021 Open Access This article is licensed under a Creative Commons Attribution 4.0 International License, which permits use, sharing, adaptation, distribution and reproduction in any medium or format, as long as you give appropriate credit to the original author(s) and the source, provide a link to the Creative Commons licence, and indicate if changes were made. The images or other third party material in this article are included in the article's Creative Commons licence, unless indicated otherwise in a credit line to the material. If material is not included in the article's Creative Commons licence and your intended use is not permitted by statutory regulation or exceeds the permitted use, you will need to obtain permission directly from the copyright holder. To view a copy of this licence, visit http://creativecommons.org/licenses/by/4.0/. The Creative Commons Public Domain Dedication waiver (http://creativecommons.org/publicdomain/zero/1.0/) applies to the data made available in this article, unless otherwise stated in a credit line to the data. 


\section{Background}

Adolescent pregnancy is a global public health problem that affects both developed and developing countries [1]. Nearly $25 \%$ of adolescent women have got pregnant worldwide [1-3], and the prevalence of adolescent pregnancy in Africa is 18.8\%, of this, $19.3 \%$ occurred in SubSaharan Africa and $21.5 \%$ in eastern Africa [2]. The prevalence of adolescent pregnancy in eastern Africa ranges from 18 to $29 \%$ and around half of these pregnancies are unintended [4].

Globally an estimated 3.9 million adolescents experience unsafe abortions, which contribute to the highest maternal mortality and morbidity [5, 6]. Adolescent pregnancy is considered the leading cause of newborn and maternal mortality in developing countries [7-9]. Pregnancies among adolescents are associated with several adverse health, educational, social and economic outcomes $[10,11]$. Adolescent pregnancies typically occur in poor populations, which could be influenced by poverty, lack of education, and work opportunities [12].

Adolescent pregnancy has significant health, psychological and socioeconomic impacts on the mother. It increases the risk of low birth weight, premature delivery, mortality, preeclampsia, social isolation, delayed or neglected educational goals, and maternal depression [8]. The social consequence includes stigma, rejection, violence and drops out of school [13, 14]. Due to their direct association with adolescent sexual intercourse, several biological factors such as the timing of pubertal development, hormone levels, and genes, are also related to adolescent pregnancy [15]. In general, adolescent mothers had a low level of education and low level of antenatal care and faces a higher risk of developing pregnancy-induced hypertension (PIH), Preeclampsia toxemia [16], eclampsia, premature labor onset, and premature delivery with increased risk of neonatal morbidity and mortality $[3,17,18]$.

Previous studies showed that being sexually active at an early age, early marriage, older teenage, married women, educational attainment, age at 1st sex, household wealth, family structure, exposure to media, community poverty level, and contraceptive use are significantly associated with adolescent pregnancy $[3,4,13,19,20]$.

Though there are studies conducted on the prevalence and associated factors of adolescent pregnancy in individual east African countries $[4,7-9,16]$, there is limited evidence on the pooled prevalence and associated factors of adolescent pregnancy in the region. Therefore, this study aimed to determine the pooled prevalence and associated factors of adolescent pregnancy in East Africa based on the pooled nationally representative Demographic and Health Surveys (DHS). Thus, the findings of this study could help policymakers, and governmental and non-governmental organizations to design programs and interventions towards adolescent pregnancy and pregnancy-related complications.

\section{Methods \\ Data sources, sampling technique, and study population}

This study was a secondary data analysis based on the datasets from the most recent Demographic and Health Surveys (DHS) conducted in East African countries (Burundi, Ethiopia, Comoros, Uganda, Rwanda, Tanzania, Mozambique, Madagascar, Zimbabwe, Kenya, Zambia, and Malawi). These datasets were appended to determine the prevalence and associated factors of adolescent pregnancy in east Africa. The DHS is a nationally representative survey that collects data on basic health indicators like mortality, morbidity, family planning service utilization, fertility, maternal and child health. The DHS used two stage stratified sampling technique to select the study participants. Each country's survey consists of different datasets including men, women, children, birth, and household datasets, and for this study, we used the women's dataset (individual record (IR) file). In this study, all adolescent girls aged 15-19 years and those who ever had sex (a total weighted sample of 17, 234) were considered for the final analysis. The detailed information on the survey country, the number of adolescents in each country, eligible and actual number of women for each country were provided in Table 1.

\section{Variables of the study}

The outcome variable of this study was "getting pregnant during the age of 15-19 years among adolescents who ever had sex". A woman was considered as experiencing adolescent/teenage pregnancy if her age was from 15 to 19 and if she had ever been pregnant before or during the survey. We used all girls age 15-19 who had ever experienced sex as our study population. The outcome was derived using the variables; the number of women who have had a birth and the number of women who have not had a birth but are pregnant at the time of interview [14].

The independent variables considered for this study were both individual and community-level variables. The individual-level factors include; the age of respondent, marital status, age at 1st sex, contraceptive use, educational attainment, household wealth status, sex of household head, relation to household head, and access to mass media. The community-level factors were community women education, community poverty, community contraceptive utilization, residence and country. In DHS, except country and residence, all the other variables were collected at the individual level. Therefore, we generate three community-level variables such as community women's education, community poverty, and community contraceptive utilization by aggregating the 
Table 1 Survey and sample size characteristics

\begin{tabular}{llllll}
\hline Country & $\begin{array}{l}\text { Year of } \\
\text { survey }\end{array}$ & $\begin{array}{l}\text { Total adolescent girls } \\
\text { interviewed }\end{array}$ & $\begin{array}{l}\text { Sample size by } \\
\text { design }\end{array}$ & $\begin{array}{l}\text { Selected adolescent } \\
\text { girls }\end{array}$ & $\begin{array}{l}\text { \% of completed } \\
\text { responses }\end{array}$ \\
\hline Burundi & 2016 & 3968 & 562 & 562 & $100 \%$ \\
Ethiopia & 2016 & 3498 & 905 & 905 & $100 \%$ \\
Kenya & 2014 & 6078 & 2233 & 2228 & $99.77 \%$ \\
Comoros & 2012 & 1295 & 285 & 285 & $100 \%$ \\
Madagascar & 2008 & 4034 & 2223 & 2223 & $100 \%$ \\
Malawi & $2015 / 16$ & 5273 & 2670 & 2670 & $100 \%$ \\
Mozambique & 2011 & 3065 & 2044 & 2044 & $100 \%$ \\
Rwanda & 2352 & 2779 & 558 & 558 & $100 \%$ \\
Tanzania & $2015 / 16$ & 2932 & 1356 & 1356 & $100 \%$ \\
Uganda & 2016 & 4276 & 1957 & 1956 & 1879 \\
Zambia & 2018 & 3686 & 1883 & 708 & $99.94 \%$ \\
Zimbabwe & $2013 / 2014$ & 2156 & 708 & $17,384^{\mathrm{a}}$ & $99.78 \%$ \\
Total & & $43,040^{\mathrm{a}}$ & & & $100 \%$ \\
\hline
\end{tabular}

Note: ${ }^{\mathrm{a}}=$ Unweighted frequency

individual-level factors at cluster level and categorized as high and low based on the median value (Table 2).

\section{Data management and analysis}

Data extraction, recoding and analysis were done using STATA version 14 software. The data were weighted before any statistical analysis to restore the representativeness of the data and to get a reliable estimate and standard error. Descriptive statistics were done using frequencies and percentages. Since the DHS data has a hierarchical structure, this violates the independent assumptions of the standard logistic regression model, a multilevel logistic regression analysis was used. Besides, adolescents in the same cluster are more likely to be similar to each other than adolescents from another cluster. This implies that there is a need to take in to account the between cluster variability by using advanced models such as multilevel analysis. The Interclass Correlation Coefficient (ICC) and Median Odds Ratio (MOR) were checked to assess whether there was clustering or not. In this study, four models were fitted; the null model- a model without explanatory variables, model I- a model with individual-level factors, model IIa model with community-level factors, and model III- a model with both individual and community-level factors, simultaneously. Model comparison was done based on deviance $(-2 \mathrm{LL})$ and a model with the lowest deviance was selected as the best-fitted model. Both bivariable and multivariable analysis was done using the best-fitted model. At the bivariable analysis variables with a $p$-value $\leq 0.2$ were considered for multivariable analysis. Finally, variables with a $P$-value of $\leq 0.05$ in the multivariable analysis were considered a significant factor associated with adolescent pregnancy.

\section{Results}

Socio-demographic characteristics

A total of 17, 234 (weighted) adolescent girls who ever had sex was included for the final analysis. Nearly threefourths $(73.78 \%)$ of the respondent were rural dwellers and more than half $(59.54 \%)$ of the respondents were aged 18 to 19 years. About $57.64 \%$ of respondents had attained primary education and $39.48 \%$ of respondents were from rich households. The majority $(70.43 \%)$ of adolescent girls had media exposure and $69.51 \%$ of respondents were from male-headed households. More than half $(53.54 \%)$ of adolescent girls were unmarried and $76.92 \%$ of adolescent girls did not use any contraceptive (Table 3).

\section{Prevalence of teenage pregnancy in East Africa}

The overall prevalence of teenage pregnancy in East Africa was $54.6 \%(95 \% \mathrm{CI} ; 53.85,55.34 \%)$, ranged from $36.15 \%$ in Rwanda to $65.29 \%$ in Zimbabwe (Fig. 1).

\section{Factors associated with adolescent pregnancy in East Africa Random effect model and model fitness}

The random effect model has been assessed using ICC, MOR, and PCV. The ICC value in the null model was 0.10 , which indicates that about $10 \%$ of the total variation in adolescent pregnancy was attributable due to the difference between clusters with the remaining $90 \%$ of the total variability in adolescent pregnancy was attributable due to the between-individual variability. Besides, the MOR value was 4.7 and this indicates that adolescent pregnancy was significantly different between clusters. Furthermore, PCV was highest in the final model (model III), which indicated that about $86 \%$ of 
Table 2 Description and measurement of independent variables

\begin{tabular}{|c|c|}
\hline \multicolumn{2}{|c|}{ Independent variables and their description/categorization } \\
\hline \multicolumn{2}{|l|}{ Individual level variables } \\
\hline Age Group & Current age of the women and re-coded in to two categories with values of "0" for 15-17, "1" for 18-19. \\
\hline Wealth Index & $\begin{array}{l}\text { The datasets contained wealth index that was created using principal components analysis coded as "poorest", } \\
\text { "poorer", "Middle", "Richer", and "Richest in the EDHS data set." For this study we recoded it in to three categories as } \\
\text { "poor" (includes the poorest and the poorer categories), "middle", and "rich" (includes the richer and the richest } \\
\text { categories) }\end{array}$ \\
\hline Occupation & Re-coded in two categories with a value of "0" for not working, and "1" for working. \\
\hline Media exposure & $\begin{array}{l}\text { A composite variable obtained by combining whether a respondent reads newspaper/magazine, listen to radio, and } \\
\text { watch television with a value of " } 0 \text { " if a women were not exposed to at least one of the three medias, and " } 1 \text { " if a } \\
\text { woman has access/exposure to at least one of the three medias. }\end{array}$ \\
\hline Educational status & $\begin{array}{l}\text { This is the minimum educational level a woman achieved and re-coded in to three groups with a value of " } 0 \text { " for no } \\
\text { education, "1" for primary education, and " } 2 \text { " for secondary and above (combining secondary and higher education } \\
\text { categories together). }\end{array}$ \\
\hline Marital status & $\begin{array}{l}\text { This was the current marital status of women and recoded in two categories with a value of " } 0 \text { " for unmarried } \\
\text { (includes those who were never in union, divorced, widowed, and separated), and " } 1 \text { " for "married" (includes those } \\
\text { living with partner and those who are married) }\end{array}$ \\
\hline Sex of household & The variable sex of household head was recorded as male and female in the dataset and we used without change. \\
\hline $\begin{array}{l}\text { Relation to house hold } \\
\text { head }\end{array}$ & $\begin{array}{l}\text { The variable relation to house hold head was recoded as " } 0 \text { " for head/spouse, "1" for Daughter and "2" for relative or } \\
\text { other based on DHS guide. }\end{array}$ \\
\hline Age at first sex & $\begin{array}{l}\text { The variable age at first sex was recoded as " } 0 \text { " for women who initiate sex at age of } 5-14 \text { " } 1 \text { " for initiation of sex at } \\
15-17 \text { "2" for women who initiate sex at the age of } 18-19 \text {. }\end{array}$ \\
\hline Contraceptive usage & $\begin{array}{l}\text { Recoded in to two categories with value of } 0 \text { for "no" if a women don't use any of the contraceptive methods, and } 1 \\
\text { for "Yes" if a women use any of the contraceptive methods. of either of or combination of the following } \\
\text { methods(female sterilization, male sterilization, contraceptive pill, intrauterine contraceptive device, injectable, } \\
\text { implants, female condom, male condom, diaphragm, contraceptive foam and contraceptive jelly, lactational } \\
\text { amenorrhea method, standard days method, and respondent-mentioned other modern contraceptive methods (in- } \\
\text { cluding cervical cap, contraceptive sponge,) }\end{array}$ \\
\hline \multicolumn{2}{|l|}{ Community level variables } \\
\hline $\begin{array}{l}\text { Community of poverty } \\
\text { level }\end{array}$ & $\begin{array}{l}\text { Measured by proportion of households in the poor (combination of poorer and poorest) wealth quintile derived } \\
\text { from data on wealth index. Then it was categorized based on national median value as: low (communities in which } \\
<50 \% \text { of women had poor socioeconomic status) and high (communities in which } \geq 50 \% \text { of women had poor } \\
\text { socioeconomic status) poverty level. }\end{array}$ \\
\hline $\begin{array}{l}\text { Community educational } \\
\text { level }\end{array}$ & $\begin{array}{l}\text { Measured by the proportion of educated women (combination of primary, secondary and higher education). It was } \\
\text { categorized based on national media value as: low (community in which }>50 \% \text { of women had no education) and } \\
\text { high (community with }>50 \% \text { of women had utilization of any of the contraceptive methods). }\end{array}$ \\
\hline $\begin{array}{l}\text { Community contraceptive } \\
\text { utilization }\end{array}$ & $\begin{array}{l}\text { Measured by using the proportion of women who used any or the combination of the contraceptives. It was } \\
\text { categorized based on national media value as: low (community in which }>50 \% \text { of women didn't use any } \\
\text { contraceptive methods) and high (community with }>50 \% \text { of women had education attainment). }\end{array}$ \\
\hline Type of place of residence & The variable place of residence recorded as rural and urban in the dataset was used without change. \\
\hline
\end{tabular}

the variation in adolescent pregnancy was explained by both individual and community-level factors. Regarding model fitness, the final model (Model III) was the bestfitted model for the data since it had the lowest deviance (Table 4).

\section{Fixed effect analysis results}

Variables including sex of household head, country and community level of education were excluded from multivariable analysis since their $p$-value at bivariable analysis was greater than 0.2 . In the multivariable multilevel binary logistic regression analysis; age of respondent, marital status, relation to the household head, age at first sex, wealth status, contraceptive use, educational level, exposure to media, working status, and community level of contraceptive use were found statistically significant factors associated with adolescent pregnancy.

The odds of adolescent pregnancy among adolescent girls aged $18-19$ years were $3.06(\mathrm{AOR}=3.06,95 \% \mathrm{CI}$ : $2.83,3.31$ ) times higher than adolescent girls aged 1517 years. Unmarried adolescent girls had 75\% (AOR = 0.25 ; $95 \%$ CI: $0.23,0.28$ ) lower odds of being pregnant at the age of 15-19 years as compared with married adolescent girls. Adolescent girls who used contraceptives had $1.41[\mathrm{AOR}=1.41 ; 95 \% \mathrm{CI}: 1.28,1.55]$ times higher odds of becoming pregnant during the adolescent period as compared to their counterparts. Besides, adolescents in the rich household had $36 \%$ ( $\mathrm{AOR}=0.64 ; 95 \% \mathrm{CI}$ : 0.58 , 0.71 ) lower odds of adolescent pregnancy as compared to adolescents from a poor household. The odds of 
Table 3 Sociodemographic characteristics of study participants

\begin{tabular}{|c|c|c|}
\hline Variables & & $\begin{array}{l}\text { Weighted frequency } \\
\text { (\%) }\end{array}$ \\
\hline \multirow[t]{2}{*}{ Age of respondent } & $15-17$ & $6977(40.46 \%)$ \\
\hline & $18-19$ & $10,268(59.54 \%)$ \\
\hline \multirow[t]{3}{*}{ Wealth status } & Poor & $6998(40.58 \%)$ \\
\hline & Middle & $3440(19.95 \%)$ \\
\hline & Rich & $6808(39.48 \%)$ \\
\hline \multirow[t]{2}{*}{ Sex of house hold head } & Male & $11,986(69.51 \%)$ \\
\hline & Female & $5259(30.49 \%)$ \\
\hline \multirow[t]{2}{*}{ Residence } & Rural & $12,724(73.78 \%)$ \\
\hline & Urban & $4521(26.22 \%)$ \\
\hline \multirow[t]{2}{*}{ Media exposure } & Yes & $12,145(70.43 \%)$ \\
\hline & No & $5101(29.57 \%)$ \\
\hline \multirow[t]{2}{*}{ Marital statues } & Married & $8012(46.46 \%)$ \\
\hline & Unmarried & 9233 (53.54\%) \\
\hline \multirow[t]{2}{*}{ Contraceptive use } & Yes & $3980(23.08 \%)$ \\
\hline & No & $13,265(76.92 \%)$ \\
\hline \multirow[t]{3}{*}{ Relation to house hold head } & Head/spouse & 5625 (32.62\%) \\
\hline & Daughter & $6106(35.41 \%)$ \\
\hline & Relative or other & $5512(31.96 \%)$ \\
\hline \multirow[t]{2}{*}{ Respondent working statues } & Working & $8603(49.89 \%)$ \\
\hline & Not working & $8642(50.11 \%)$ \\
\hline \multirow[t]{3}{*}{ Educational level } & No education & $1428(8.28 \%)$ \\
\hline & Primary education & 9938 (57.64\%) \\
\hline & $\begin{array}{l}\text { Secondary } \\
\text { education }\end{array}$ & $5876(34.08 \%)$ \\
\hline \multirow[t]{3}{*}{ Age at first sex } & $5-14$ & $4555(26.43 \%)$ \\
\hline & $15-17$ & $10,714(62.17 \%)$ \\
\hline & $18-19$ & 1965 (11.40\%) \\
\hline \multirow[t]{2}{*}{ Community poverty } & Low & $8403(48.73 \%)$ \\
\hline & High & 8842 (51.27\%) \\
\hline \multirow{2}{*}{$\begin{array}{l}\text { Community-women educational } \\
\text { level }\end{array}$} & Low & 8870 (51.43\%) \\
\hline & High & 8375 (48.57\%) \\
\hline \multirow{2}{*}{$\begin{array}{l}\text { Community contraceptive } \\
\text { utilization }\end{array}$} & Low & $7862(45.59 \%)$ \\
\hline & High & $9383(54.41 \%)$ \\
\hline \multirow[t]{12}{*}{ Country } & Burundi & 567 (3.28\%) \\
\hline & Ethiopia & $832(4.82 \%)$ \\
\hline & Kenya & 2169 (12.58\%) \\
\hline & Comoros & $270(1.56 \%)$ \\
\hline & Madagascar & 2117 (12.28\%) \\
\hline & Malawi & 2734 (15.85\%) \\
\hline & Mozambique & 2029 (11.77\%) \\
\hline & Rwanda & $557(3.23 \%)$ \\
\hline & Tanzania & 1515 (8.78\%) \\
\hline & Uganda & 1947 (11.29\%) \\
\hline & Zambia & 1781 (10.33\%) \\
\hline & Zimbabwe & 728 (4.22\%) \\
\hline
\end{tabular}

adolescent pregnancy among adolescent girls who started sexual intercourse at the age of $15-17$ years, and $18-19$ years were 0.69 ( $\mathrm{AOR}=0.69$; 95\% CI: $0.63,3.75$ ), and 0.31 ( $\mathrm{AOR}=0.31 ; 95 \% \mathrm{CI}: 0.27,0.35)$ times lower as compared to those who started intercourse at the age of 5-14 years, respectively. The odds of being pregnant during the adolescent period was 1.11 times $(\mathrm{AOR}=$ 1.11; 95\% CI: 1.03, 1.19) higher among employed girls compared to their counterparts. The odds of teenage pregnancy among adolescent girls who were spouse/ head with in the family were also higher compared to being a daughter $[\mathrm{AOR}=1.62$; $95 \% \mathrm{CI}$ : $1.45,1.82]$. Looking at media exposure, adolescent girls who had exposure to media had 0.85 times $(\mathrm{AOR}=0.85 ; 95 \% \mathrm{CI}$ : 0.78 , 0.92) lower odds of being pregnant during the adolescent period compared to their counterparts. Adolescent girls with secondary and higher education had lower odds of being pregnant during adolescence compared with uneducated adolescent girls $(\mathrm{AOR}=0.78 ; 95 \% \mathrm{CI}$ : $0.68,0.91)$. Regarding community-level contraceptive utilization, adolescent girls from the community with a higher level of contraceptive use had 1.10 times $(\mathrm{AOR}=$ 1.10; 95\%CI: 1.02, 1.19) higher odds of being pregnant compared with their counterparts (Table 5).

\section{Discussion}

This study aimed to assess the pooled prevalence and associated factors of adolescent pregnancy in east Africa using the pooled DHS data. The pooled prevalence of teenage pregnancy in this study was $54.6 \%$ (95\% CI: $53.85,55.34 \%$ ), ranging from $36.15 \%$ in Rwanda to $65.29 \%$ in Zimbabwe. It is higher than the report of previous studies $[2,4,9]$. This might be due to the difference in the study population since we have incorporated any form of pregnancy such as terminated pregnancy as teenage pregnancy, unlike other studies. The other possible explanation might be because of the large sample size and we included participants from different countries with a wide variety of socioeconomic status and cultural norms [19].

In this study; respondent age, contraceptive utilization, marital status, media exposure, respondent working status, household wealth status, community-level contraceptive utilization, age at first sex, educational level and relation to the household head were significantly associated with adolescent pregnancy. The odds of adolescent pregnancy were higher among older teenagers and this is supported by a study done in Africa [11]. This might be due to the fact that as age increases, teenagers will have more exposure to sex and their chance of getting married will also increase to procreate children [15]. Besides, older teenagers had the chance to separate from their parents and started to live independently which may lead them to have risky sexual behavior. 


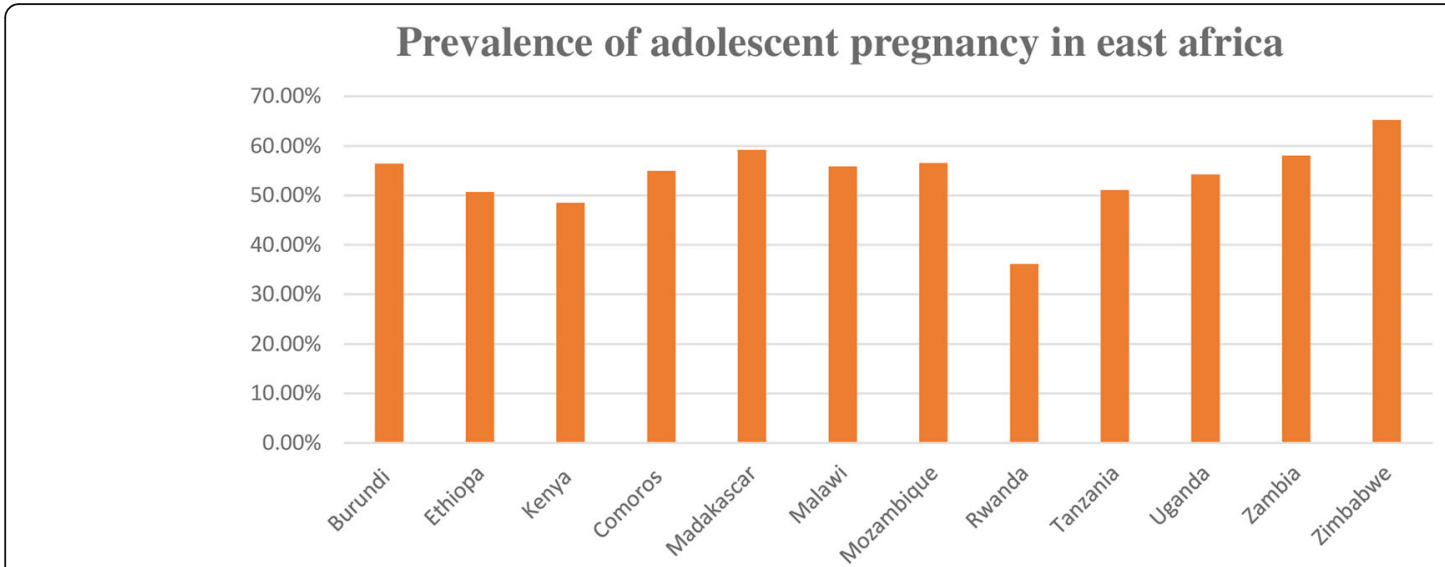

Fig. 1 Prevalence of teenage pregnancy among adolescent girls in eastern Africa countries

Surprisingly, in our study, adolescent girls who used contraceptives were at higher risk of teenage pregnancy which is in contrast to different studies $[3,19]$. This may be correlated with even though there is increased use of contraception in developing countries, still a contraceptive failure, due to inadequate contraceptive counseling, awareness, and utilization skills, is common and this results in unplanned and unwanted pregnancy [17]. The higher rate of teenage pregnancy among contraceptive users also indicates that contraceptive needs may still be unmet, including intermittent use of contraceptives and supply interruption [18].

Adolescent girls from rich households had a lower risk of teenage pregnancy compared with adolescent girls from poor economic classes. This is widely accepted and in agreement with a study in Africa [19]. This may be because adolescent girls from poor households may be exposed to early marriage and sexual initiation and can't afford the cost of reproductive health services and contraceptives [19]. Also, adolescents from families of low socioeconomic status are at greater risk of early and unintended pregnancies largely due to poverty and lower expectations of future economic success [4]. This may also be justified as young people from higher poverty levels may be involved in transactional sex as an economic survival strategy and this leads to pregnancy at a

Table 4 Random effect model and model fitness for the assessment of pregnancy among young women in eastern Africa

\begin{tabular}{lll}
\hline Parameter & Empty model & Final model \\
\hline ICC & 0.100677 & .005415 \\
PCV & Ref & 0.865 \\
MOR & 4.7 & 3.4 \\
model comparison & & \\
$\quad$ Log likelihood & $-11,988.704$ & -9291.7749 \\
Deviance & $23,977.408$ & $18,583.5498$ \\
\hline
\end{tabular}

younger age [9]. In this study, early sexual initiation is a risk factor for teenage pregnancy, which is in agreement with another study done in Ethiopia [19]. This may be because women with early sexual initiation had less information, knowledge, attitude, and practice about safe sex and modern contraceptive utilization $[18,19]$.

The study at hand also revealed that adolescents of being spouse/head are at increased risk of teenage pregnancy, which is in line with studies in eastern Africa $[4,20]$. This might be due to adolescent girls who didn't live with both of their biological parents' lack their parental support and guidance which exposes them to early sexual initiation, pregnancy and early motherhood [4].

Married adolescent girls had higher odds of being pregnant, which is in agreement with a study in Ethiopia [11]. Similarly, an employed adolescent girls had higher odds of teenage pregnancy compared with unemployed girls which is supported by a study done in sub-Saharan Africa [9]. This may be because adolescent girls are exposed to different risky sexual behaviors at their workplace and this sexual assault leads to pregnancy [21]. Interestingly, adolescent girls who had exposure to media had lower odds of being pregnant. This may be justified by exposure to various mass media can encourage adolescents to utilize maternal health services such as youth reproductive services and family planning services [22]. Mass media exposure also offers improved awareness and understanding, as well as improvements in attitudes, social expectations and behaviors that can contribute to beneficial effects for public health [16]. Adolescent girls who had secondary and higher education had a lower chance of being pregnant early, which is supported by a study conducted in sub-Saharan Africa [9]. This may be explained because education increases autonomy and decision-making power and increases economic independence, leading to the postponement of marriage, and reduction of fertility [23]. 
Table 5 The bi-variable and multivariable multilevel binary logistic regression analysis of factors associated with adolescent pregnancy in East Africa in the final model

\begin{tabular}{|c|c|c|c|c|c|}
\hline \multirow[t]{2}{*}{ Variables } & & \multicolumn{2}{|c|}{ Teenage pregnancy } & \multirow[t]{2}{*}{$\operatorname{COR}(95 \% \mathrm{Cl})$} & \multirow[t]{2}{*}{ AOR(95\%Cl) } \\
\hline & & Yes & No & & \\
\hline \multirow[t]{2}{*}{ Respondent age } & $15-17$ & 2808 & 4169 & 1 & 1 \\
\hline & 18-19 & 6607 & 3660 & $2.88(2.70,3.07)$ & $3.06(2.83,3.31)^{*}$ \\
\hline \multirow[t]{3}{*}{ Highest educational level } & No education & 999 & 429 & 1 & 1 \\
\hline & Primary education & 5997 & 3941 & $0.68(0.62,0.76)$ & $1.20(1.00,1.37)$ \\
\hline & Secondary and above & 2418 & 3458 & $0.31(0.28,0.35)$ & $0.78(0.68,0.91)^{*}$ \\
\hline \multirow[t]{3}{*}{ Wealth status } & Poor & 4511 & 2487 & 1 & 1 \\
\hline & Middle & 1996 & 1443 & $0.77(0.71,0.84))$ & $1.01(0.91,1.11)$ \\
\hline & Rich & 2909 & 3898 & $0.41(0.38,0.43)$ & $0.64(0.58,0.71)^{*}$ \\
\hline \multirow[t]{2}{*}{ Respondent current working } & working & 5090 & 3513 & $1.47(1.39,1.56)$ & $1.11(1.03,1.19)^{*}$ \\
\hline & Not working & 4327 & 4315 & 1 & 1 \\
\hline \multirow[t]{2}{*}{ Marital statues } & Married & 6216 & 1796 & 1 & 1 \\
\hline & Unmarried & 3200 & 6033 & $0.51(0.14,0.16)$ & $0.25(0.23,0.28)^{*}$ \\
\hline \multirow[t]{2}{*}{ contraceptive use } & Yes & 2550 & 1431 & $1.65(1.53,1.78)$ & $1.41(1.28,1.55)^{*}$ \\
\hline & No & 6867 & 6398 & 1 & 1 \\
\hline \multirow[t]{2}{*}{ Media exposure } & Yes & 6151 & 5994 & $0.57(0.54,0.61)$ & $0.85(0.78,0.92)^{*}$ \\
\hline & No & 1835 & 3265 & 1 & 1 \\
\hline \multirow[t]{2}{*}{ Residence } & Urban & 1996 & 2525 & 1 & 1 \\
\hline & Rural & 5304 & 7420 & $1.79(1.68,1.92)$ & $1.02(0.93,1.12)$ \\
\hline \multirow[t]{3}{*}{ Relation to house hold head } & Head/spouse & 4495 & 1131 & $6.04(5.57,6.57)$ & $1.62(1.45,1.82)^{*}$ \\
\hline & Relative or other & 2418 & 3004 & $1.15(1.02,1.24)$ & $0.89(0.82,1.01)$ \\
\hline & Daughter & 2502 & 3605 & 1 & 1 \\
\hline \multirow[t]{3}{*}{ Age at first sex } & $5-14$ & 2620 & 1935 & 1 & 1 \\
\hline & $15-17$ & 5891 & 4823 & $0.88(0.82,0.95)$ & $0.69(0.63,0.75)^{*}$ \\
\hline & 18-19 & 904 & 1060 & $0.65(0.58,0.72)$ & $0.31(0.27,0.35)^{*}$ \\
\hline \multirow[t]{2}{*}{ Community poverty level } & Low & 3479 & 4018 & 1 & 1 \\
\hline & High & 5937 & 3811 & $1.16(1.09,1.24)$ & $1.00(0.92,1.07)$ \\
\hline \multirow[t]{2}{*}{ Community contraceptive } & Low & 3839 & 4023 & 1 & 1 \\
\hline & High & 5393 & 3990 & $1.22(1.14,1.30)$ & $1.10(1.02,1.19)^{*}$ \\
\hline
\end{tabular}

\section{Strength and limitation of the study}

The study has many strengths, first, the study was based on weighted nationally representative data from 12 eastern African countries with large sample size. Second, the multilevel analysis was used to accommodate the hierarchical nature of the DHS data to get reliable standard error and estimate. Moreover, since it is based on the national survey data the study has the potential to give insight for policy-makers and program planners to design appropriate intervention strategies both at national and regional levels. However, this study had limitations in that the DHS survey was based on respondents' selfreport, this might have the possibility of recall bias. Besides, since this study was based on survey data, we are unable to show the temporal relationship between adolescent pregnancy and independent variables. Also, the independent variables for adolescent girls who gave childbirth (pregnant before) were measured at the time of the survey date.

\section{Conclusion}

In this study, the pooled prevalence of teenage pregnancy was higher, indicating that teenage pregnancy is still the major public health problem in east Africa. Respondent's age, contraceptive utilization, marital status, respondent working status, household wealth status, community poverty level, initiation of sex at an earlier age, residence, and relation to the household head had a significant association with teenage pregnancy. So, emphasis should be given to the reduction and prevention 
of pregnancy in adolescent girls to prevent adverse maternal, neonatal, educational and economic outcomes. Besides, African countries should have an integrated approach for the improvement of sexual health promotion and early pregnancy prevention among adolescent girls and women with poor socioeconomic status.

\section{Abbreviations}

Cl: Confidence Interval; CSA: Central Statistical Agency; DHS: Demographic Health Survey; EA: Enumeration Area; ICC: Intraclass correlation; LLR: Likelihood Ratio; WHO: World Health Organization; PIH: Pregnancyinduced hypertension; PET: Preeclampsia toxemia; MOR: Median odds ratio; PCV: Proportional Change in Variance

\section{Acknowledgments}

We greatly acknowledge MEASURE DHS for granting access to the Demographic and Health Surveys data.

\section{Authors' contributions}

GAT, MGW, ABT, YY, and ZTT conceived the study. GAT, MGW, ABT, YY, and ZIT analyzed the data. GAT, MGW, ABT, YY, and ZTT drafted the manuscript and reviewed the article. All authors read and approved the final manuscript.

\section{Funding}

No funding was obtained for this study.

\section{Availability of data and materials}

All result-based data are within the manuscript and the data set is available online and anyone can access it from www.measuredhs.com.

\section{Declarations}

\section{Ethics approval and consent to participate}

Since the study was a secondary data analysis of publically available survey data from the MEASURE DHS program, ethical approval and participant consent were not necessary for this particular study. We requested DHS Program and permission was granted to download and use the data for this study from http://www.dhsprogram.com. The Institution Review Board approved procedures for DHS public-use datasets do not in any way allow respondents, households, or sample communities to be identified. There are no names of individuals or household addresses in the data files. The geographic identifiers only go down to the regional level (where regions are typically very large geographical areas encompassing several states/ provinces)

\section{Consent for publication}

Not applicable since the study was a secondary data analysis already collected by CSA.

\section{Competing interests}

Authors declare that they have no conflict of interest.

\section{Author details}

'Department of Human Anatomy, College of Medicine and Health Science, School of Medicine, University of Gondar, Gondar, Ethiopia. ${ }^{2}$ Department of Epidemiology and Biostatistics, Institute of Public Health, College of Medicine and Health Sciences, University of Gondar, Gondar, Ethiopia. ${ }^{3}$ Department of Human Physiology, College of Medicine and Health Science, School of Medicine, University of Gondar, Gondar, Ethiopia.

Received: 22 June 2020 Accepted: 15 March 2021

Published online: 26 March 2021

\section{References}

1. Klein JD. Adolescent pregnancy: current trends and issues. Pediatrics. 2005; 116(1):281-6. https://doi.org/10.1542/peds.2005-0999.

2. Kassa GM, Arowojolu A, Odukogbe A, Yalew AW. Prevalence and determinants of adolescent pregnancy in Africa: a systematic review and meta-analysis. Reprod Health. 2018;15(1):195. https://doi.org/10.1186/s12978018-0640-2
3. Kaphagawani N, Kalipeni E. Sociocultural factors contributing to teenage pregnancy in Zomba district, Malawi. Glob Public Health. 2017;12(6):694710. https://doi.org/10.1080/17441692.2016.1229354.

4. Wado YD, Sully EA, Mumah JN. Pregnancy and early motherhood among adolescents in five east African countries: a multi-level analysis of risk and protective factors. BMC Pregnancy Childbirth. 2019;19(1):59. https://doi.org/1 0.1186/s12884-019-2204-z.

5. Darroch JE, Woog V, Bankole A, Ashford LS, Points K. Costs and benefits of meeting the contraceptive needs of adolescents: Guttmacher Institute; 2016.

6. Franklin C, Corcoran J. Preventing adolescent pregnancy: a review of programs and practices. Soc Work. 2000;45(1):40-52. https://doi.org/10.1093/ sw/45.1.40.

7. Neal S, Matthews Z, Frost M, Fogstad H, Camacho AV, Laski L. Childbearing in adolescents aged 12-15 years in low resource countries: a neglected issue. New estimates from demographic and household surveys in 42 countries. Acta Obstet Gynecol Scand. 2012;91(9):1114-8. https://doi.org/1 0.1111/j.1600-0412.2012.01467.x.

8. WHO. Global health estimates 2015: deaths by cause, age, sex, by country and by region, 2000-2015. Geneva: World Health Organization; 2016.

9. Odimegwu C, Mkwananzi S. Factors associated with teen pregnancy in subSaharan Africa: a multi-country cross-sectional study. Afr J Reprod Health. 2016;20(3):94-107. https://doi.org/10.29063/ajrh2016/v20i3.14

10. Ochen AM, Chi PC, Lawoko S. Predictors of teenage pregnancy among girls aged 13-19 years in Uganda: a community based case-control study. BMC Pregnancy Childbirth. 2019;19(1):211. https://doi.org/10.1186/s12 884-019-2347-y

11. Ayele BG, Gebregzabher TG, Hailu TT, Assefa BA. Determinants of teenage pregnancy in Degua Tembien District, Tigray, Northern Ethiopia: A community-based case-control study. PLoS One. 2018;13(7):e0200898.

12. Unicef UN. Progress and prospects. End Child Marriage Prog Prospect UNICEF [Internet]. 2014:1-8

13. Okigbo CC, Speizer IS. Determinants of Sexual Activity and Pregnancy among Unmarried Young Women in Urban Kenya: A Cross-Sectional Study. PLoS One. 2015;10(6):e0129286.

14. Croft TN, Aileen M, Courtney K. Guide to DHS Statistics: DHS-7. Rockville; 2018.

15. Ayanaw Habitu Y, Yalew A, Azale BT. Prevalence and factors associated with teenage pregnancy, Northeast Ethiopia, 2017: a cross-sectional study. J Pregnancy. 2018;2018:1-7. https://doi.org/10.1155/2018/1714527.

16. Asp G, Pettersson KO, Sandberg J, Kabakyenga J, Agardh A. Associations between mass media exposure and birth preparedness among women in southwestern Uganda: a community-based survey. Glob Health Action. 2014;7(1):22904. https://doi.org/10.3402/gha.v7.22904.

17. Larsson M, Aneblom G, Odlind V, Tydén T. Reasons for pregnancy termination, contraceptive habits and contraceptive failure among Swedish women requesting an early pregnancy termination. Acta Obstet Gynecol Scand. 2002:81(1):64-71. https://doi.org/10.1046/j.0001-6349.2001.00169.x.

18. Sedgh G, Ashford LS, Hussain R. Unmet need for contraception in developing countries: examining women's reasons for not using a method. New York: Guttmacher Institute. 2016;2:2015-6.

19. Birhanu BE, Kebede DL, Kahsay AB, Belachew AB. Predictors of teenage pregnancy in Ethiopia: a multilevel analysis. BMC Public Health. 2019;19(1): 601. https://doi.org/10.1186/s12889-019-6845-7.

20. Brahmbhatt $\mathrm{H}$, Kågesten $\mathrm{A}$, Emerson $\mathrm{M}$, Decker $\mathrm{MR}$, Olumide $\mathrm{AO}$, Ojengbede O, Lou C, Sonenstein FL, Blum RW, Delany-Moretlwe S. Prevalence and determinants of adolescent pregnancy in urban disadvantaged settings across five cities. J Adolesc Health. 2014;55(6):S4857. https://doi.org/10.1016/j.jadohealth.2014.07.023.

21. Garrett LH. Sexual assault in the workplace. AAOHN J. 2011;59(1):15-22. https://doi.org/10.1177/216507991105900103.

22. Fatema K, Lariscy JT. Mass media exposure and maternal healthcare utilization in South Asia. SSM - Population Health. 2020;11:100614. https:// doi.org/10.1016/j.ssmph.2020.100614

23. Undie C-C, MacKenzie I, Birungi $\mathrm{H}$, Barongo S, Ahindukha D, Omondi C Education sector response to early and unintended pregnancy: a policy dialogue in Homa Bay County, Kenya; 2015.

\section{Publisher's Note}

Springer Nature remains neutral with regard to jurisdictional claims in published maps and institutional affiliations. 